\title{
PERLUASAN HUTAN KOTA DAN EXPLORATORIUM ALAM DI PAMULANG
}

\author{
Fila Ferari ${ }^{1)}$, Tony Winata ${ }^{2)}$ \\ 1)Program Studi S1 Arsitektur, Fakultas Teknik, Universitas Tarumanagara, isabellafila15@gmail.com \\ ${ }^{2)}$ Program Studi S1 Arsitektur, Fakultas Teknik, Universitas Tarumanagara, tonywinata@ft.untar.ac.id

\begin{abstract}
Abstrak
Bumi merupakan rumah bagi semua makhluk hidup di dalamnya yang terdiri dari berbagai macam unsur pembentuk seperti air, udara, tanah, suhu, cahaya, kelembaban, manusia, flora, fauna, dan lain-lain. Kehidupan yang terjadi merupakan wujud hasil dari hubungan interaksi antara sesama makhluk hidup maupun dengan lingkungannya, yang disebut dengan ekologi. Arsitektur hadir sebagai wadah, habitat dan relung bagi semua makhluk hidup untuk berkembang dan bertumbuh. Kota merupakan bukti dari evolusi manusia yang di dalamnya dapat memenuhi semua kebutuhan kehidupan, dan tanpa disadari perkembangan ini mendorong terjadinya fenomena over population. Hal tersebut berjalan seiring dengan krisis lahan dan hilangnya hutan kota (RTH) akibat dari fenomena yang terjadi. Proyek ini bertujuan untuk mengangkat kembali dan meningkatkan esensi hutan kota, serta menjadi generator hijau di kota yang mengalami krisis RTH demi menjaga keseimbangan ekosistem dan lingkungan hidup. Hal ini dicapai dengan melampaui peran yang dimiliki oleh hutan kota dan manusia pada umumnya untuk menciptakan dampak yang lebih besar bagi kehidupan. Hal ini difasilitasi dengan habitat bagi tumbuhan dan hewan, kegiatan berolahraga, ruang belajar, bermain, memancing, dan sebagainya.
\end{abstract}

Kata kunci: exploratorium alam; habitat; hutan kota; krisis RTH; lingkungan hidup

\begin{abstract}
Earth is home to all living things in it which consists of various kinds of forming elements such as water, air, soil, temperature, light, humidity, humans, flora, fauna, and others. Life is the result of the interaction between fellow living things with their environment, which is called ecology. Architecture exists as a place, habitat, and niche for all living things to develop and grow. Cities are evidence of human evolution in which they can meet all the needs of life, and without realizing this development has led to the overpopulation phenomenon. This goes hand in hand with the land crisis and the loss of urban forest (green open space) as a result of this phenomenon. This project aims to re-elevate and enhance the essence of urban forests and become green generators in cities experiencing green open space crises, in order to maintain the balance of ecosystems and the environment. This will be achieved by going beyond the role played by urban forests and humans in general to create a greater impact on life. This is facilitated by habitats for plants and animals, sports activities, study rooms, playgrounds, fishing, and etc.
\end{abstract}

Keywords: environment; exploratorium; green open space crisis; habitat; urban forest

\section{PENDAHULUAN Latar Belakang}

Dewasa ini, keseimbangan lingkungan alam sangat terancam karena perkembangan industri yang semakin meningkat demi kepentingan hidup manusia. Hal ini berakar pada sebuah pandangan atau anggapan antroposentrisme yang sudah tertanam kuat di manusia modern dan tindakan-tindakannya, yang dimana menganggap bahwa manusia merupakan pusat dari segalanya (eksklusif). Pandangan ini tercermin melalui perilaku manusia modern mengeksploitasi alam yang mengakibatkan kerusakan pada lingkungan hidup. 
Populasi penduduk kota Tangerang selalu meningkat setiap tahunnya dan diprediksikan akan memuncak sebesar 36\% di tahun 2040 dengan total 3.6 juta jiwa. Terdapat beberapa hal yang menyebabkan peningkatan populasi manusia yaitu, imigrasi dan natalitas. Seiring dengan berjalannya peningkatan populasi penduduk, kebutuhan hidup yang harus dipenuhi juga akan semakin meningkat. Manusia akan melakukan pembangunan untuk memenuhi kebutuhan akan tempat tinggal yang dimana akan melakukan alih fungsi lahan dan akan berakibat pada penurunan lahan hijau yang digunakan untuk menjaga keseimbangan ekosistem. Luas RTH yang tersedia baru mencapai $20 \%$ dari luas minimum ideal (30\%), perluasan RTH di kota ini masih perlu untuk ditingkatkan dan tetap dipertahankan eksistensinya, jangan sampai lahan-lahan tersebut dialihfungsikan atau dieksploitasi demi kepentingan evolusi manusia pada masa mendatang. Menurunnya kualitas dan kuantitas ruang terbuka publik yang ada di perkotaan, baik ruang terbuka hijau (RTH) dan ruang terbuka non hijau telah mengakibatkan menurunnya kualitas lingkungan perkotaan seperti sering terjadi banjir, tingginya polusi udara, dan menurunnya produktivitas masyarakat akibat rasa jenuh karena terbatasnya ruang publik yang tersedia untuk berinteraksi sosial bagi masyarakat (Purnomohadi, Ruang Terbuka Hijau: Sebagai Unsur Utama Tata Ruang Kota, 2002).

Hutan kota merupakan salah satu bagian dari RTH yang memiliki banyak manfaat mulai dalam aspek ekologis, psikologis dan juga sosial. Namun hutan kota dinilai kurang berdampak untuk aspek ekonomi sehingga cenderung dianggap rendah, diabaikan dan dialihfungsikan. Kondisi ini yang menyebabkan peran RTH tidak dapat berjalan dengan maksimal dan bukan menjadi prioritas untuk dikembangkan atau dipelihara. Peran masyarakat dalam menjaga keseimbangan kelestarian lingkungan alam ini sangat besar. Hutan kota dilestarikan bukan hanya untuk kepentingan masyarakat namun juga sebagai habitat dari flora dan fauna yang hidup di dalamnya, serta memiliki peran dalam menjaga lingkungan alam untuk mencapai keseimbangan. Jika eksploitasi terhadap lahan terus dilakukan, bukan hanya berdampak kepada flora dan fauna tetapi akan kembali ke manusia. Oleh karena itu, salah satu solusi untuk menangani ini adalah dengan escalated urban forest dan exploratorium. Dengan meningkatkan peran hutan kota agar memiliki dampak yang lebih besar dan luas bagi alam maupun makhluk hidup dan juga berkontribusi pada penambahan luas RTH di kota agar keseimbangan ekosistem tetap terjaga.

\section{Rumusan Permasalahan}

Bagaimana cara meningkatkan peran hutan kota sehingga dapat menjadi generator untuk masa depan serta berdampak besar bagi alam dan makhluk hidup? Apa program fungsi bangunan yang dapat meningkatkan kepedulian dan pengetahuan masyarakat terhadap hutan kota dengan metode wisata?

\section{Tujuan}

Tujuan dari proyek Escalated Urban Forest dan Exploratorium adalah menjadi generator / proyek pilot dan berkontribusi dalam perluasan ruang terbuka hijau di kota untuk meminimalisir dampak buruknya bagi lingkungan serta meningkatkan peran hutan kota bukan hanya dalam aspek ekologis, psikologis dan sosial tetapi juga memiliki dampak terhadap ekonomi lokal, pendidikan dan kesehatan masyarakat. Dengan mempelajari peran dan manfaat hutan kota saat ini yang dipadukan dengan perkembangan teknologi, proyek ini akan menjadi generator untuk memaksimalkan peran hutan kota dan masyarakat demi menjaga kelestarian lingkungan hidup. Program dalam proyek ini juga mengacu pada agenda dunia yang tercantum pada Sustainable Development Goals untuk mencapai masa depan yang berkelanjutan, meliputi empat poinnya yaitu poin nomor 3, good health and well-being yang dimana kesehatan fisik dan mental masyarakat adalah salah satu cara untuk meningkatkan kualitas hidup. Maka proyek ini akan 
menjadi penghasil oksigen dan penyerap karbon serta menghilangkan stress. Poin nomor empat, quality education, pendidikan merupakan hal mendasar yang tidak bisa lepas dari kehidupan manusia. Dengan meningkatkan pengetahuan tentang hutan kota akan menciptakan generasi dengan tingkat kepedulian tinggi. Poin nomor tujuh, affordable and clean energy, melalui menghasilkan energi ramah lingkungan untuk digunakan kembali bukan hanya menggunakan energi terbarukan untuk menjaga lingkungan hidup. Dan poin nomor 15, life on land, untuk melindungi dan memperbaiki ekosistem hutan serta mencegah kepunahan habitat dan keanekaragaman hayati dengan meningkatkan peran hutan kota untuk berkontribusi menciptakan kehidupan yang lebih baik bagi makhluk hidup dan lingkungannya (Sustainable Development Goals, 2015).

\section{KAJIAN LITERATUR}

Ekologi adalah ilmu yang mempelajari baik interaksi antar makhluk hidup maupun interaksi antara makhluk hidup dan lingkungannya. Ekologi berasal dari kata Yunani oikos ("habitat") dan logos ("ilmu"). Dalam ekologi, makhluk hidup dipelajari sebagai kesatuan atau sistem dengan lingkungannya. Terdapat beberapa komponen penunjang keseimbangan ekosistem, yaitu faktor abiotik dan biotik. Faktor abiotik antara lain cahaya, kelembaban, air, suhu, dan tanah sedangkan faktor biotik adalah makhluk hidup yang terdiri dari hewan, tumbuhan, mikroba, dan manusia. Ekologi juga berhubungan erat dengan tingkatan-tingkatan organisasi makhluk hidup yaitu populasi, komunitas dan ekosistem yang saling terikat dan mempengaruhi untuk menunjang kesatuan dalam kehidupan. Pembagian ekologi menurut taksonomi ke dalam 3 hal yaitu ekologi tumbuhan yang memiliki hubungan sangat erat dengan faktor cahaya, suhu dan air, ekologi hewan yang mempelajari interaksi antara hewan dengan lingkungannya, dan ekologi manusia menurut Amos H. Hawley (1950: 67), "Human ecology may be defined, therefore, in terms that have already been used, as the study of the form and the development of the community in human population." Ekologi manusia bisa dikatakan dalam kondisi yang sudah ditentukan bahwa yaitu sebagai media pembelajaran dan pengembangan sebuah komunitas dalam populasi manusia (Martono, 2020).

Berdasarkan Peraturan Pemerintah Republik Indonesia Nomor 63 Tahun 2002 Tentang Hutan Kota Pasal 1 Ayat 3, hutan kota adalah sebuah hamparan lahan yang bertumbuhan pohon-pohon yang kompak dan rapat di dalam wilayah perkotaan baik pada tanah negara maupun tanah hak, yang ditetapkan sebagai hutan kota oleh pejabat yang berwenang. Dalam pasal 2 disampaikan, tujuan penyelenggaraan hutan kota adalah untuk kelestarian, keserasian, dan keseimbangan ekosistem perkotaan yang meliputi unsur lingkungan, sosial, dan budaya. Dalam pasal 3 disampaikan, hutan kota memiliki fungsi sebagai berikut, memperbaiki dan menjaga iklim mikro dan nilai estetika kawasan, meresapkan air, menciptakan keseimbangan dan keserasian lingkungan fisik kota, mendukung pelestarian keanekaragaman hayati Indonesia, penyerap karbondioksida dan penghasil oksigen, penahan angin, ameliorasi iklim, habitat satwa liar, meningkatkan ekonomi lokal, mereduksi pencemaran lingkungan, peredam kebisingan, tempat pelestarian plasma nutfah dan bioindikator. Terdapat tiga jenis hutan kota yaitu, hutan kota pemukiman untuk membantu menciptakan lingkungan yang nyaman dan menambah keindahan serta menangkal polusi udara, hutan kota industri sebagai penangkal polutan yang berasal dari limbah yang dihasilkan oleh kegiatan industri, dan hutan kota wisata untuk memenuhi kebutuhan rekreasi masyarakat kota yang dilengkapi sarana bermain dan tempat istirahat (Indonesia, 2002).

Selain itu dalam Tantangan Lingkungan dan Lansekap Hutan Kota (Zoer'aini, 2008) terdapat fungsi hutan kota yaitu sebagai identitas kota yang dapat menjadi simbol kota, nilai estetika dengan mempertimbangkan komposisi yang dirancang dalam hutan, pepohonan dan jenis flora lainnya dapat memberi kesan alam yang berbeda diantara kota yang dipenuhi oleh bangunan, 
penyerap karbondioksida dan penghasil oksigen untuk makhluk hidup yang berada disekitarnya, pelestarian air tanah untuk penurunan tingkat erosi tanah, mencegah penurunan muka tanah, penahan angin dengan tanaman yang memiliki daya tahan tinggi, ameliorasi iklim untuk menurunkan suhu pada siang hari, habitat satwa liar untuk meningkatkan keanekaragaman hayati hutan tersebut serta sebagai wadah perlindungan, pelestarian dan penyedia nutrisi, meningkatkan ekonomi lokal melalui perdagangan atau pemanfaatan hasil hutan kota berupa bunga, buah, getah dan kayu. Selain itu juga menjadi mata pencaharian masyarakat setempat berupa area wisata, restoran, café, mereduksi pencemaran lingkungan yang memiliki dampak buruk bagi semua makhluk hidup, peredam kebisingan dengan beberapa jenis tanaman yang dapat mengurangi kebisingan yang timbul akibat aktivitas manusia, tempat pelestarian plasma nutfah dan bioindikator dari timbulnya masalah lingkungan seperti hujan asam. (Hastanto, 2013). Daun tanaman dapat menyerap kebisingan hingga 95\% (Grey \& Deneke, 1978).

Exploratorium adalah suatu tempat wisata ilmiah interaktif yang terdiri dari perpaduan museum ilmiah dan tempat rekreasi (Andrian, 2003). Istilah Exploratorium berasal dari kata eksplorasi dan auditorium (Moser, Penny, Ward: Fischer, George, 1988: 84). Berdasarkan pada hal diatas, maka istilah exploratorium dapat didefinisikan sebagai auditorium eksplorasi untuk tempat pembelajaran ilmu pengetahuan, yang mengarah pada suatu wadah yang menggabungkan beberapa objek pameran dengan pendekatan seni yang diimplementasikan menjadi wisata edukasi bagi masyarakat. Exploratorium memiliki tujuan untuk menciptakan suatu budaya pembelajaran yang baru melalui inovasi yang dikembangkan tentang lingkungan alam sekitar melalui berbagai program dan elemen pendukung yang dapat mempermudah dalam penyampaian informasi.

Menurut Penny Ward Moser dan Georg Fischer (1988), dalam exploratorium terdapat berbagai kegiatan diantaranya permainan cahaya, suara dan musik, seni permainan warna, elektrisitas, suhu/temperatur, pendengaran, sentuhan, penglihatan, gelombang dan resonansi, cuaca dan kelembaban, angin dan udara, dan hal lain yang sifatnya dapat ditemui dalam kegiatan seharihari dan ditampilkan dengan hal yang baru. Untuk mencapai tujuan tersebut, terdapat cara untuk memenuhinya yaitu, menciptakan lingkungan dan budaya pembelajaran yang inovatif, sebagai media interaksi antara manusia dan pengetahuan melalui sudut pandang yang berbeda, yaitu dengan mendekatkan diri melalui keindahan seni (Andrian, 2003).

\section{METODE DESAIN}

Pada buku Biophilic Design: The Theory, Science and Practice of Bringing Buildings to Life yang dikeluarkan oleh Stephen R. Kellert, William Browning dan Jenifer Seal-Cramer disampaikan bahwa ada nilai yang menjadi referensi bagi desain biophilic yang disebut sebagai 14 pattern of biophilic design yang terdiri dari 3 kategori utama dan 14 parameter didalamnya, nature in the space. Hal ini dilengkapi dengan 7 parameter didalamnya yaitu, koneksi visual dengan alam, koneksi non-visual dengan alam, sensor stimuli non-ritmik, thermal dan variasi aliran udara, air, cahaya yang dinamis dan tersebar, dan koneksi antar sistem natural. Kategori kedua yaitu natural analogues, terdapat 3 parameter dalam kategori ini yaitu, bentuk dan pola biomorphic, koneksi material dengan alam, dan kompleksitas dan keteraturan. Kategori ketiga yaitu nature of the space dengan 4 parameter desain dalam kategori ini yaitu, prospect, refuge, misteri dan resiko / bahaya (Kellert, Heerwagen, \& Mador, 2008). Biophilic design memiliki tujuan untuk mendekatkan kembali hubungan antara manusia dengan alam sekitarnya melalui ruang-ruang yang diciptakan, hal ini sejalan dengan visi yang dimiliki oleh proyek ini yaitu selain untuk sebagai contributor RTH, tapi juga untuk meningkatkan kepedulian masyarakat dengan alam. Maka dari itu perancangan ruang-ruang pada hutan kota dan exploratorium alam ini didasari pada nilai yang menjadi referensi dengan pengaplikasian dalam desain sebagai berikut: 


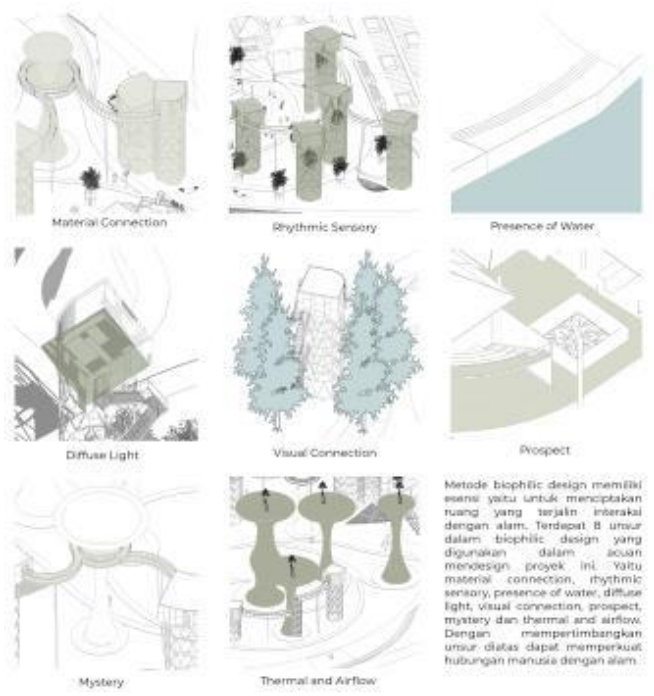

Gambar 1. Pengaplikasian Metode Perancangan Sumber: Penulis, 2021

Pengaplikasian metode dalam desain dengan 8 aspek (lih. Gambar 1) yaitu, material connection pengaplikasian material Cross Laminated Timber untuk menciptakan kesan menyatu dengan alam. Rhythmic sensory, yang dimana menunjukkan pengulangan ritme bangunan. Presence of water, menciptakan ruang terbuka (promenade) dengan pengalaman ruang baru agar manusia dapat melihat, mendengar, menyetuh elemen air. Diffuse light dengan memanfaatkan intensitas cahaya yang masuk ke dalam bangunan secara dinamis dan menyebar dengan alami sebagai wujud perubahan waktu yang terjadi pada alam (pagi-malam). Visual connection, memberikan akses kepada manusia agar dapat lebih dekat berinteraksi dengan alam. Dengan bangunan yang berada di ketinggian 10-20 meter, dapat menciptakan pengalaman baru untuk lebih dekat dengan dunia udara. Prospect, dengan mendesain ruang tanpa batasan ruang yang masif sehingga ruang didalamnya lebih leluasa dan dekat dengan alam sekitarnya. Mystery dengan sky bridge yang menciptakan suasana menarik untuk dijelajahi. Serta thermal and airflow, dengan memberikan variasi perubahan suhu dan angin.

\section{DISKUSI DAN HASIL}

Dalam proyek Escalated Urban Forest dan Exploratorium at Pamulang (Perluasan Hutan Kota dan Exploratorium Alam di Pamulang) ini, penulis memiliki visi untuk menjadikan proyek generator dan sebagai kontributor RTH bagi kota serta menjaga keanekaragaman hayati yang dimiliki. Selain itu juga menjadi wadah bagi manusia untuk mempelajari dan berkontribusi dalam kelestarian lingkungan hidup, dalam hal ini adalah hutan kota.

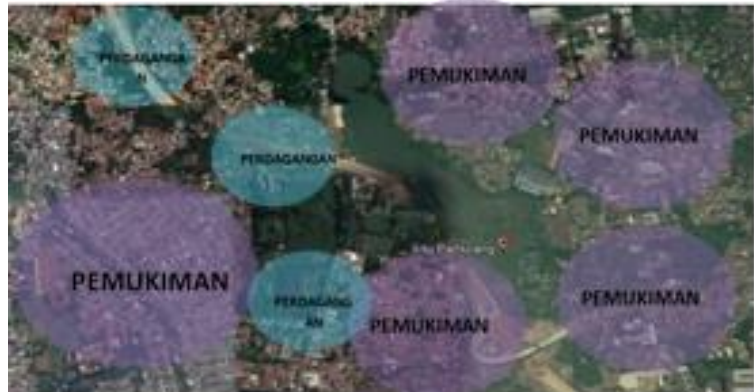

Gambar 2. Kawasan Pamulang

Sumber: Google Earth, 2021

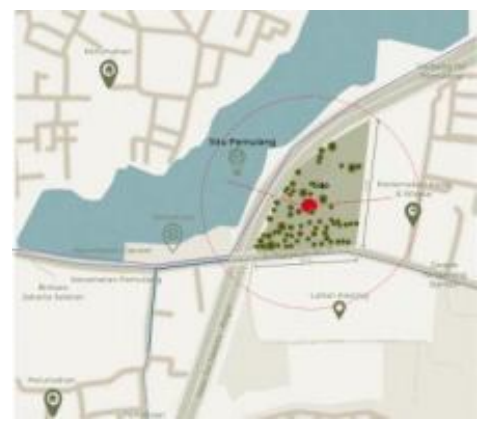

Gambar 3. Tapak Perancangan Sumber: Penulis, 2021 
Sebagai bentuk kontribusi dalam memenuhi luas RTH di Tangerang Selatan, lokasi perancangan hutan kota diambil di kecamatan Pamulang dimana yang masih memerlukan pengembangan tinggi yang merupakan kawasan pemukiman dan perdagangan. Tapak yang berada di Jl. Pajajaran No. 3, Bambu Apus, Pamulang, Tangerang Selatan memiliki keunggulan yaitu terintegrasi langsung dengan Situ Pamulang dan wisata perternakan kuda sehingga secara keseluruhan proyek ini dapat menjadi kawasan wisata serta area sekitarnya masih merupakan lahan kosong yang banyak ditumbuhi pepohonan dan terletak di jalan kolektor sehingga proyek ini dapat menjadi kontributor sekaligus generator untuk pengembangan kedepannya.
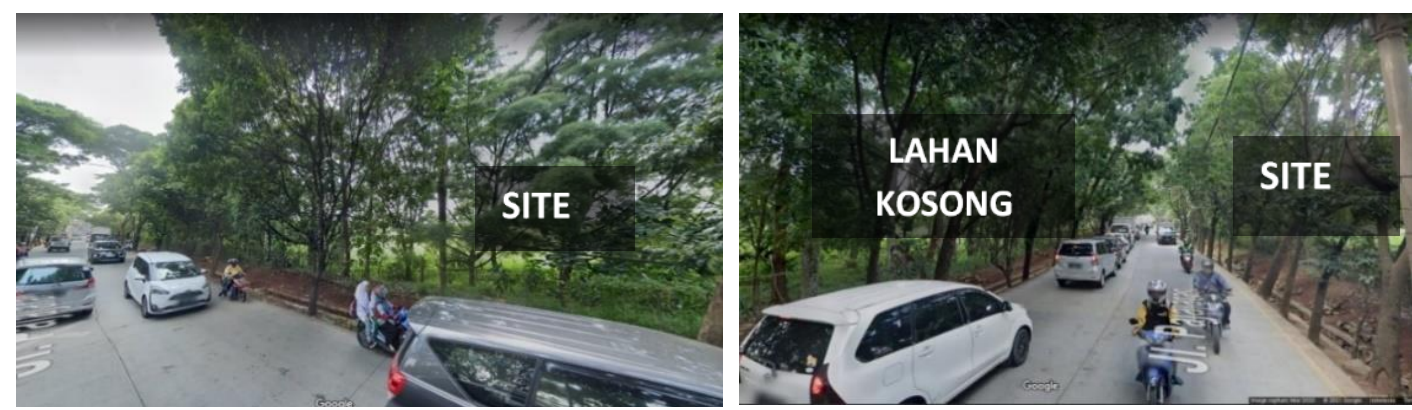

Gambar 4. Kondisi sekitar tapak

Sumber: Google Earth, 2021

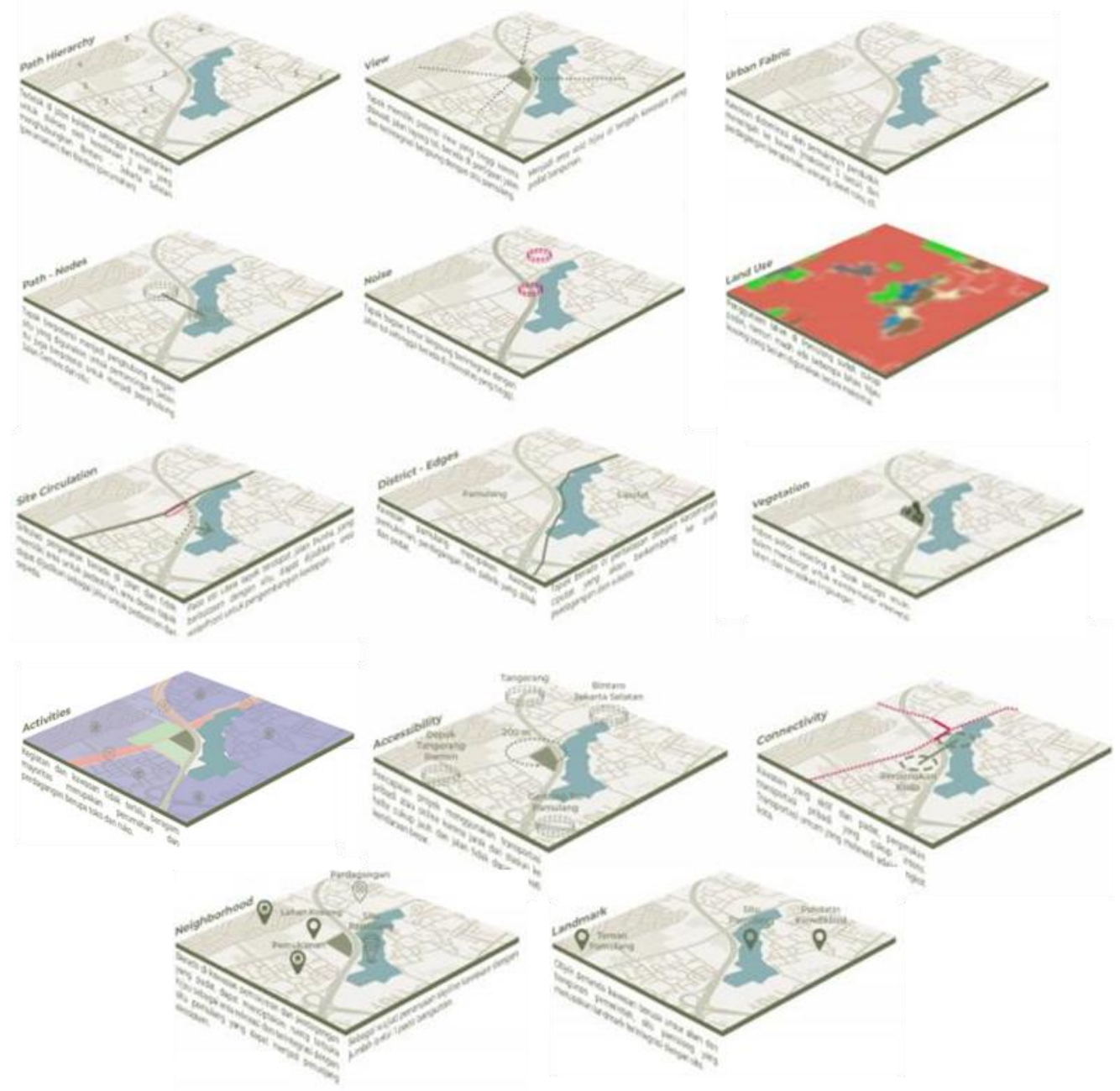

Gambar 5. Analisis Tapak

Sumber: Penulis, 2021 
Tapak ini terdeteksi dalam radius $\pm 200 \mathrm{~m}$ dikelilingi oleh pemukiman warga serta perdagangan (ruko atau bangunan tunggal) sehingga mudah dijangkau bagi mereka yang ingin berolahraga, rekreasi, bersosialisasi, dan kegiatan lainnya. Selain itu, proyek ini juga ditujukan sebagai media edukasi. Lalu tapak ini juga ditunjang melalui sekitarnya yaitu adanya Situ Pamulang yang banyak digunakan warga setempat sebagai area wisata pemancingan dan juga terdapat wisata dan perternakan kuda.

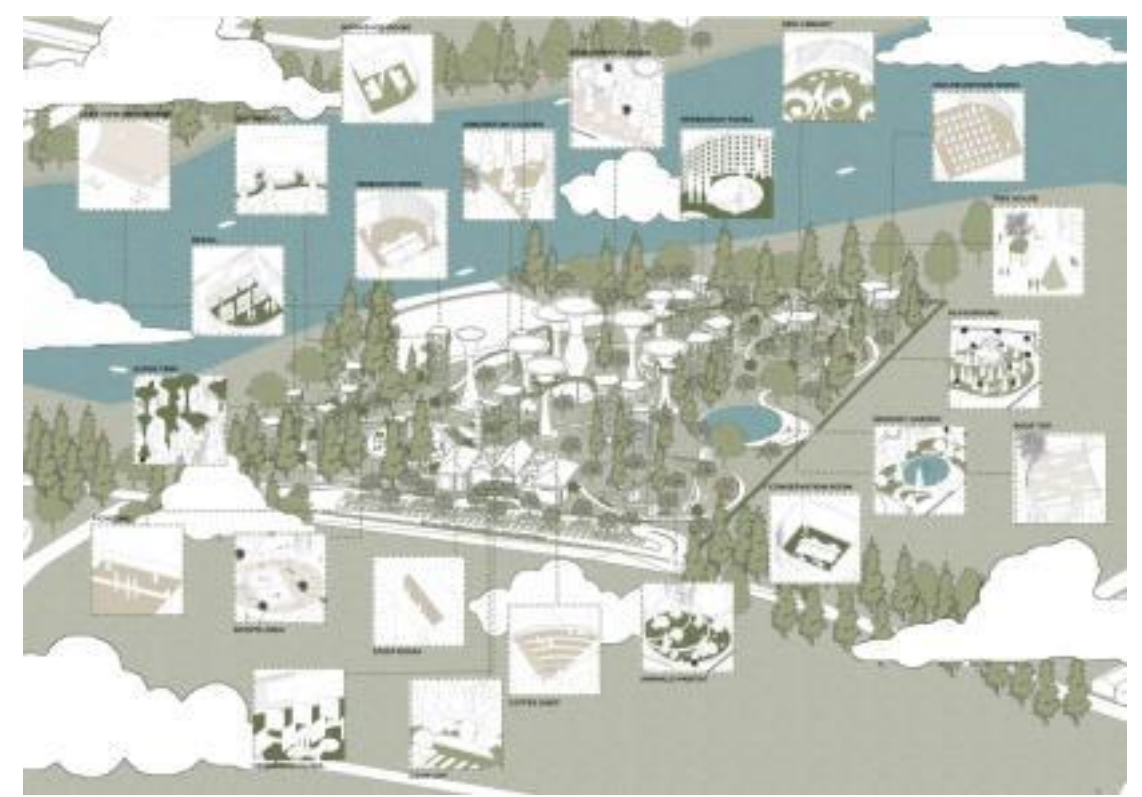

Gambar 6. Program Bangunan

Sumber: Penulis, 2021

Setelah menganalisis tapak dan tujuan proyek yang juga mengacu pada Sustainable Development Goals, kemudian diterjemahkan dalam program proyek (lihat Gambar 6) yang terdiri dari program utama yaitu escalated urban forest (70\%) terdiri dari biodynamic garden, sensory garden dan animals zone yang dimana menjawab belum terpenuhi dan maksimalnya penggunaan lahan hijau atau RTH di daerah perkotaan yang menyebabkan ketidakseimbangan ekosistem dan meningkatkan peran hutan kota, kekuatan alam dipadukan dengan teknologi dapat menjadi salah satu solusi permasalahan. Peran hutan kota disini akan ditingkatkan dengan super tree, menggunakan material bangunan yang dapat menyerap karbon, menghasilkan energi terbarukan yang dapat digunakan dan menjadi habitat bagi satwa dan tumbuhan. Untuk meningkatkan kepedulian masyarakat mengenai lingkungan hidupnya, salah satunya adalah dengan meningkatkan pengetahuan tentang lingkungan alam.

Zohar dan Marshall mengungkapkan seseorang yang memiliki kecerdasan spiritual yang tinggi cenderung menjadi seorang pemimpin yang penuh dengan pengabdian, bertanggung jawab untuk membawakan visi dan nilai yang lebih tinggi, dan dapat memberi inspirasi kepada orang lain. Hal ini juga dapat berkontribusi dalam SDG's poin nomor 4 yaitu Quality Education, yang dimana menyediakan media pembelajaran untuk generasi yang peduli lingkungan. Maka dari itu program Flora dan Fauna Exploratorium (25\%) yang terdiri dari galeri arboretum dan herbarium, laboratorium riset, ruang workshop, ruang multifungsi dan perpustakaan sebagai media pembelajaran bagi masyarakat setempat. Program penunjang (5\%) pada proyek ini terdapat area olahraga, bermain dan retail yang dapat digunakan untuk wisata edukasi, selain itu juga dapat meningkatkan perekonomian lokal melalui retail-retail yang disewakan mengingat bahwa masyarakat sekitar bergerak di dunia usaha perdagangan. 

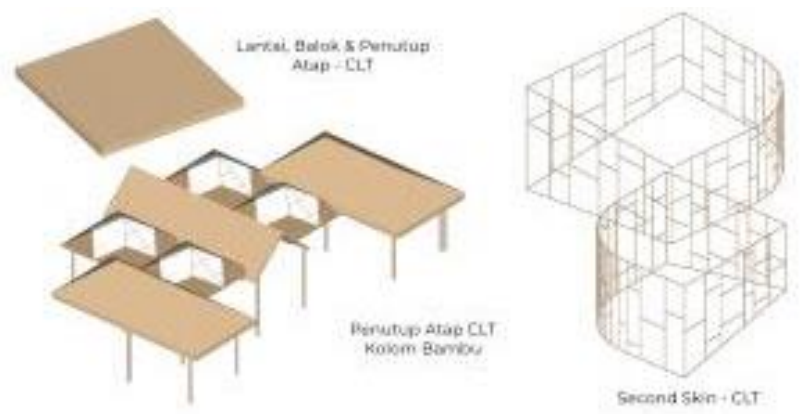

Gambar 7. Material Bangunan

Sumber: Penulis, 2021

Dalam merancang proyek ini, penulis juga menganalisis dan menerapkan 4 parameter dari Beyond Ecology. Pertama adalah Energy dan Emission, yang dimana meminimalisir penggunaan energi dan menghasilkan emisi bagi lingkungan. Hal ini diterapkan dengan meminimalisir efek karbon pada udara dengan menggunakan material alami dan hemat energi yaitu Cross Laminated Timber (CLT) pada bagian fasad bangunan, lantai, balok, rangka atap serta tangga pada bangunan serta penggunaan bambu petung sebagai kolom bangunan. Selain itu juga dapat memperkuat kesan alami dan menyatu dengan alam. Penerapan ini juga sebagai bentuk perancangan dari metode desain yaitu material connection dan thermal and airflow (Dromologi Spatial, 2021).

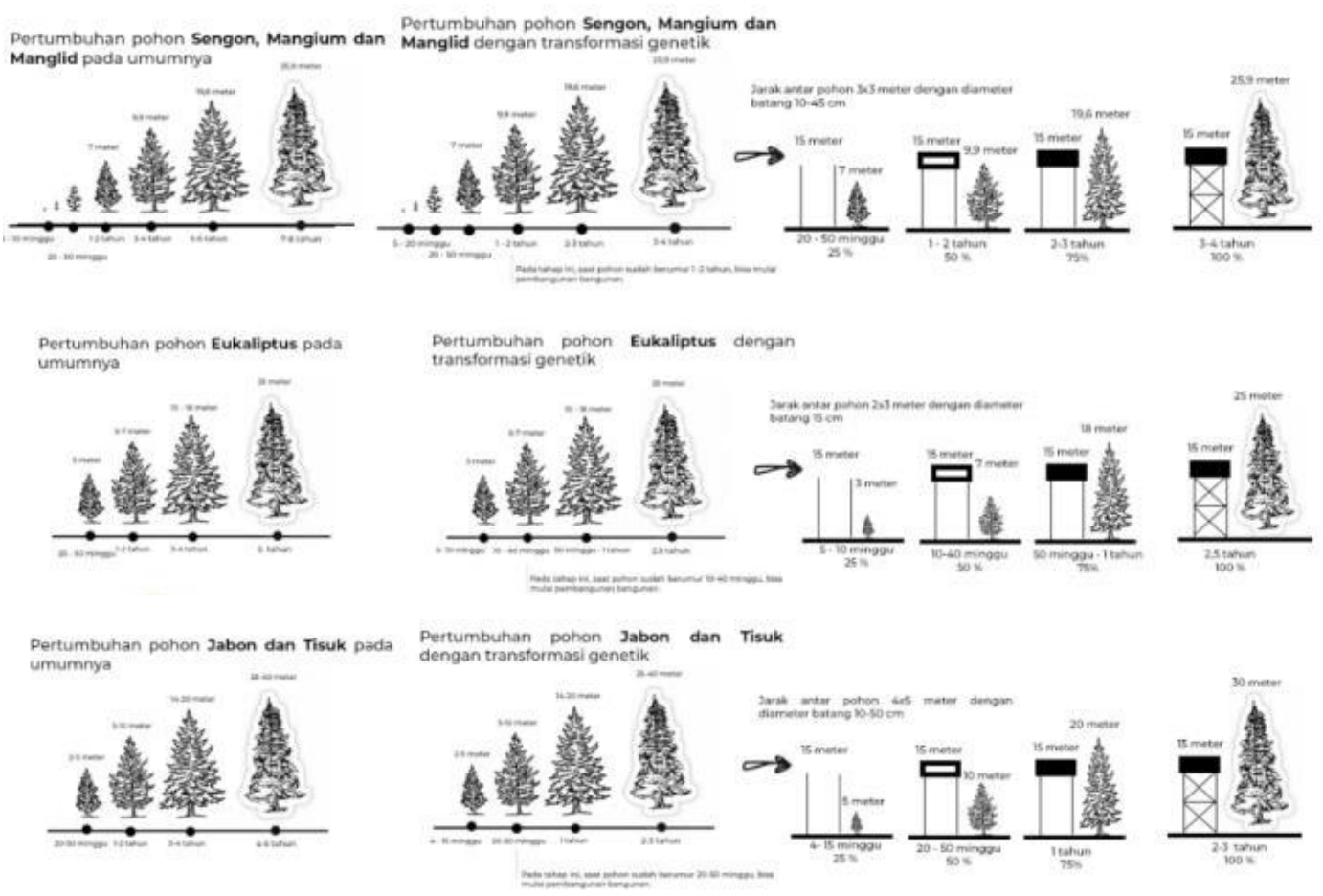

Gambar 8. Timeline Pertumbuhan Pohon

Sumber: Penulis, 2021

Kedua, adaptation yaitu dengan mengadaptasi kondisi hutan kota yang ditumbuhi pepohonan, dengan penyebaran massa yang disesuaikan dengan titik pohon yang dimana bangunan berada diantara pepohonan serta mengangkat bangunan diatas ketinggian kurang lebih 10-20 meter diatas tanah untuk meminimalisir intervensi lahan serta peran RTH dan tumbuhan tetap dapat berjalan dengan maksimal. Hal ini juga merupakan bentuk penerapan dari metode bagian visual connection pattern. 
Ketiga, context dimana membaca kondisi untuk memunculkan konsep baru yang dimana pertumbuhan pohon agar dapat berfungsi sebagai pelindung pada ketinggian dan umur tertentu memerlukan waktu pada umumnya 15-24 tahun. Dengan menggunakan teknologi baru yaitu bioteknologi transformasi genetika pohon untuk mempercepat pertumbuhan pohon yang dapat dipercepat hingga $2 x$ lipat (LIPI, 2010). Jenis pohon yang akan ditanam pada proyek ini menyesuaikan dengan kondisi tanah di Indonesia dan Banten, dan juga tergolong dalam fast growing species yaitu terdiri dari pohon Sengon, Mangium dan Manglid yang pada umumnya memerlukan waktu 7-8 tahun dipercepat sampai 3-4 tahun, pohon Jabon dan Tisuk yang pada umumnya memerlukan waktu 4-5 tahun dipercepat sampai 2-3 tahun, pohon Eukaliptus yang pada umumnya memerlukan waktu 5 tahun dipercepat sampai 2,5 tahun. Kemudian pada umur pohon terentu, dapat dimulai pembangunan bangunan. (PLPG, 2016).

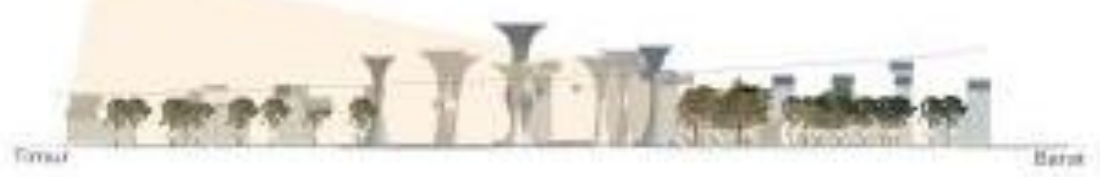

Gambar 9. Ketinggian Bangunan

Sumber: Penulis, 2021

Pertumbuhan pohon tumbuh ke arah datangnya matahari (timur), sehingga ketinggian bangunan pada sisi kiri (timur) lebih rendah dibanding sisi barat untuk mencegah penubrukan pohon terhadap bangunan dan memaksimalkan pencahayaan untuk pertumbuhan pohon. Penyebaran bibit pohon baru yang akan ditanam menyesuaikan dengan lokasi bangunan dengan jarak \pm 1-3 meter, sehingga pada saat pohon tumbuh dan bangunan akan dibangun tetap dapat berjalan. Pada bagian ini juga menerapkan nilai diffuse light, agar hubungan antara pohon dengan bangunan dapat tetap menguntungkan satu sama lainnya demi kenyamanan aktivitas di dalamnya.

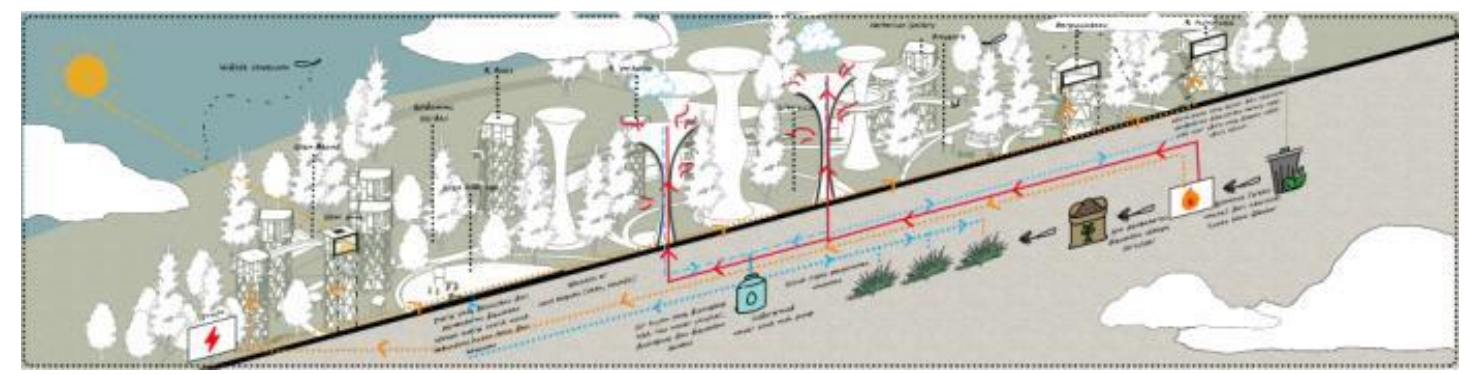

Gambar 10. Potongan Aksonometri

Sumber: Penulis, 2021

Keempat, new tech dimana teknologi baru untuk desain arsitektur yang diaplikasikan melalui super tree sebagai teknologi baru, untuk meningkatkan peran hutan kota, yang memiliki fungsi sebagai vertical garden, menyerap energi matahari untuk tumbuhan berfotosintesis, menampung air hujan yang airnya dapat digunakan kembali, menyerap dan mengolah udara kemudian dilepaskan menjadi lebih sehat, selain itu juga pada bagian atas dapat berfungsi sebagai look out tower dan habitat hewan udara bebas lainnya. Selain itu juga menunjukkan hubungan integrasi sistem dengan bangunan yang dimana biowaste (green waste) dari hutan kota dibakar untuk menciptakan energi listrik untuk kebutuhan hutan kota dan bangunan, kemudian gasnya dibuang melalui super tree ke udara. Sisa pembakaran dapat digunakan sebagai fertilizer untuk penanaman dan pencangkokkan yang hasilnya bisa untuk ditanam dan dijual. Air yang ditangkap oleh super tree diolah untuk digunakan sebagai irigasi di hutan dan bangunan. Udara panas yang dihasilkan oleh aktivitas diserap oleh super tree dan dilepas ke 
dalam udara lebih sehat yang dimana juga tercantum pada nilai biophilic design (thermal and airflow). Proses desain site plan dan gubahan massa didasari dengan konteks pohon eksisting yang tetap dipertahankan untuk meminimalisir kerusakan alam. Dengan mempelajari urban fabric kawasan Pamulang dan melakukan analisis serta beberapa studi desain maka dihasilkan tipe bangunan segi 4 untuk menciptakan kesatuan dengan lingkungan sekitar serta meningkatkan efektivitas ruang gerak di dalamnya. Kemudian massa diangkat 10-20 meter diatas tanah agar RTH dibawahnya dapat berfungsi maksimal sebagai area resapan, menjaga tanah, dll.
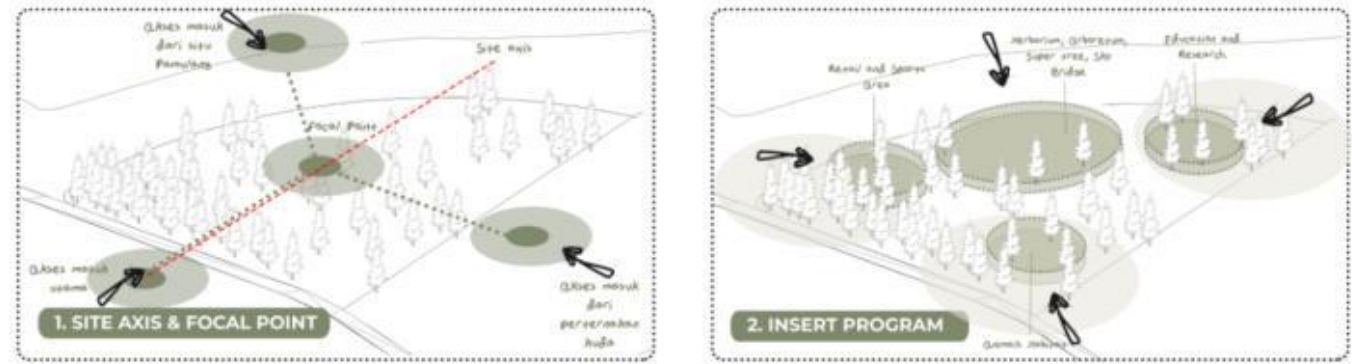

Gambar 11. Proses Pembentukan Massa 1 dan 2 Sumber: Penulis, 2021

Proses perancangannya diawali dengan menarik aksis dari 3 akses masuk ( 1 akses utama dan dua side entrance) yang berpotongan di tengah tapak (aksis tapak) dan dijadikan focal point dari proyek ini dengan penempatan super tree dan exploratorium. Kemudian mengisi tiga bagian sudut tapak dengan program retail, area olahraga dan habitat hewan yang termasuk dalam kelompok kegiatan dengan user yang lebih general dan juga sebagai magnet pada wajah utama proyek untuk menarik masyarakat sekitar. Penempatan area pengetahuan dan penelitian di belakang agar mendapatkan suasana yang lebih tenang dan privat untuk kenyamanan dan keefektivitasan kegiatan yang berjalan di dalamnya. Penempatan program outdoor dan indoor yang digabung untuk menciptakan pengalaman yang lebih kuat antara buatan dan alami yang mengacu pada metode desain.
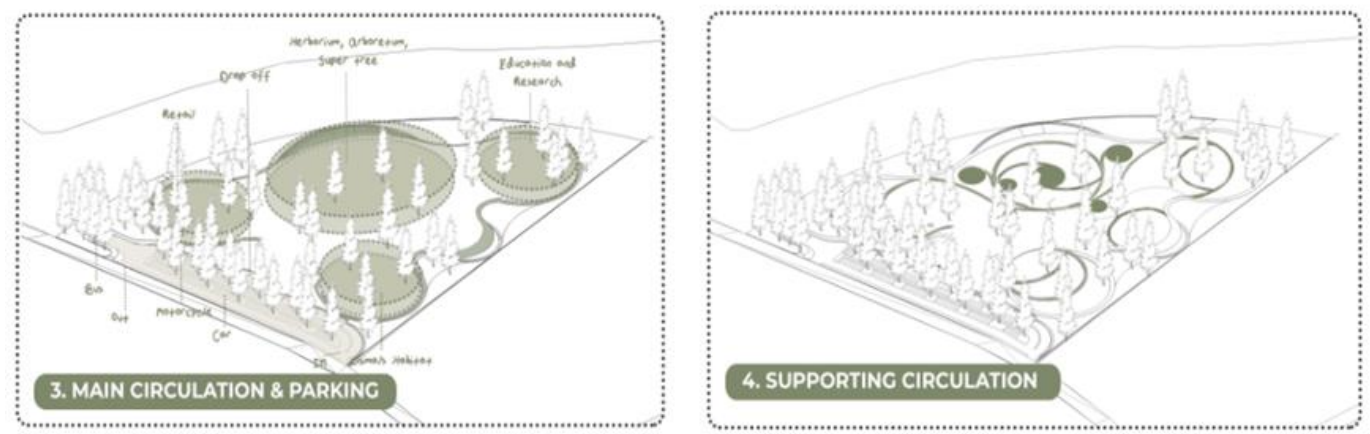

Gambar 12. Proses Pembentukan Massa 3 dan 4

Sumber: Penulis, 2021

Kemudian, membentuk sirkulasi utama mengitari tapak mengikuti pola penempatan program pada sisi luar dengan mempertimbangkan titik pohon agar sirkulasi yang tercipta lebih dinamis. Dilanjutkan dengan mengisi bagian excess dengan taman sensorik sebagai akses masuk dari perternakan kuda dan bangunan penerima pada bagian depan bangunan serta perpecahan sirkulasi sekunder untuk area yang belum tercapai dengan tujuan menciptakan pengalaman ruang yang berbeda dalam setiap perjalanan yang dilakukan oleh pengunjung. 

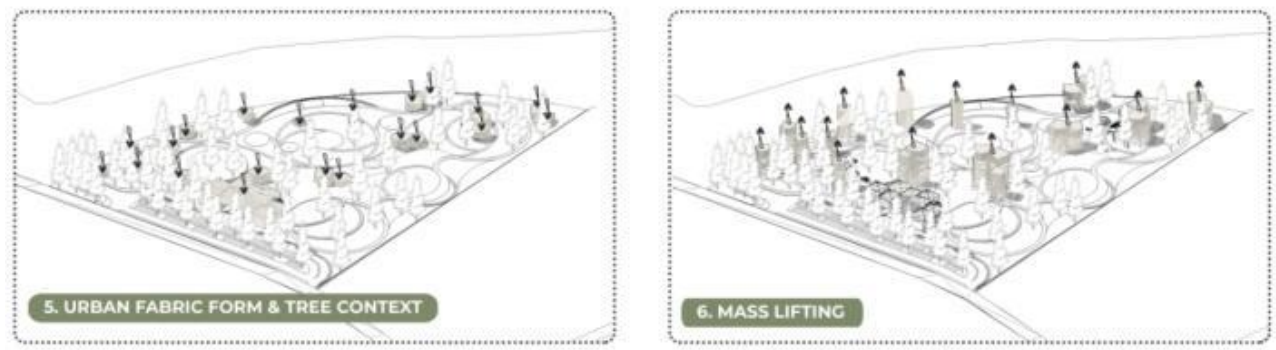

Gambar 13. Proses Pembentukan Massa 5 dan 6 Sumber: Penulis, 2021

Dengan mempelajari urban fabric kawasan Pamulang dan melakukan analisis serta beberapa studi desain maka dihasilkan tipe bangunan segi 4 untuk menciptakan kesatuan dengan lingkungan sekitar yang didominasi dengan bangunan perumahan serta meningkatkan efektivitas ruang gerak di dalamnya, penyebaran massa tunggal untuk menciptakan pengulangan (rhythmic sensori) menyesuaikan dengan titik penyebaran pohon eksisting untuk tetap mempertahankan kondisi alam yang ada sehingga tetap menjaga lingkungan alam dan tidak dirusak. Kemudian massa diangkat dengan ketinggian yang bervariasi kurang lebih 10-20 meter diatas tanah untuk menciptakan pengalaman yang dinamis serta pertimbangan arah datangnya matahari dari sebelah timur yang dinilai lebih optimal dalam proses pertumbuhan pohon dengan pengaturan skyline pada sisi timur bangunan yang lebih rendah agar pohonpohon dan tanaman dapat tumbuh secara optimal dan tidak terhalang oleh bangunan yang dimana juga sebagai bentuk penyesuaian diri terhadap hutan kota agar bisa berjalan secara maksimal dan efisien.
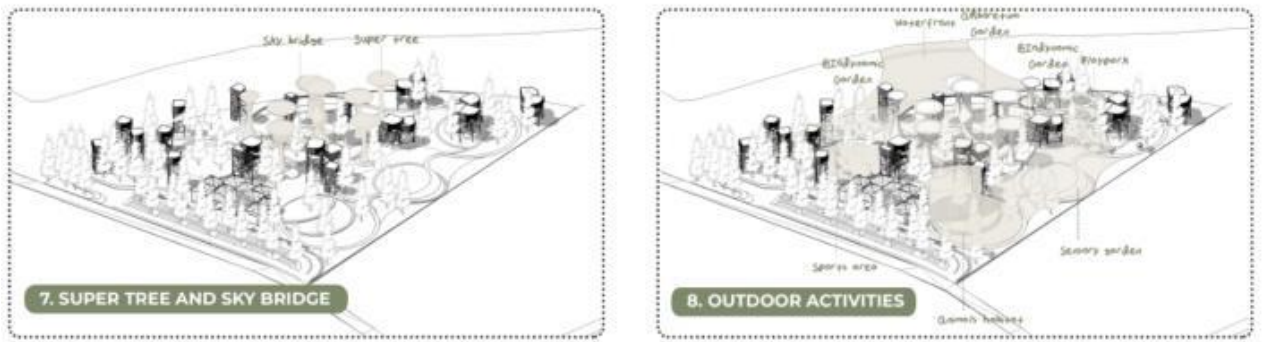

Gambar 14. Proses Pembentukan Massa 7 dan 8 Sumber: Penulis, 2021

Menempatkan super tree pada focal point tapak yang bergabung dengan galeri arboretum dan herbarium serta sky bridge yang menghubungkan antar massa dengan super tree untuk menciptakan pengalaman ruang dan efektivitas sirkulasi. Penggunaan sky bridge juga sebagai bentuk pengaplikasian biophilic design (mystery) untuk menciptakan pengalaman ruang yang unik. Kemudian melengkapi area lainnya dengan aktivitas outdoor seperti promenade, biodynamic garden, taman bermain, area olahraga, habitat hewan serta taman sensorik.

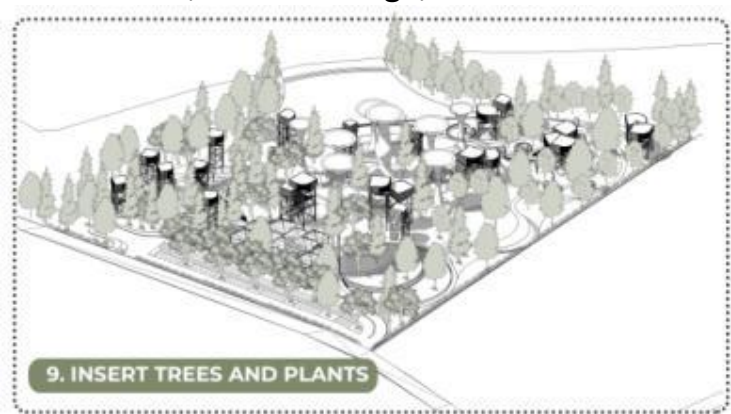

Gambar 15. Proses Pembentukan Massa 9 Sumber: Penulis, 2021 
Untuk memenuhi standar jumlah pohon dalam hutan kota, area yang masih kosong diisi dengan pohon-pohon yang termasuk dalam fast growing species yaitu pohon Sengon, Jabon, Tisuk, Manglid, Mangium, dan Eukaliptus dengan jarak antar pohon yang beragam 2-5 meter. Serta tanaman pendek (Boksus) yang digunakan sebagai barrier dan pagar tapak, pada biodynamic garden terdapat tanaman sayuran dan buah-buahan seperti, kacang-kacangan, bawang, kentang, seledri, wortel, tomat, timun, tauge, cabai, dll yang dapat dijual kembali atau dimanfaatkan oleh masyarakat setempat. Struktur utama pada bangunan menggunakan kolom baja dengan diameter $150 \mathrm{~mm}$ yang dilapisi dengan tanaman rambat yang dapat menyerap karbon di udara untuk menciptakan kesan yang menyatu dengan alam dan juga sebagai prototype pohon yaitu untuk menyerap karbon. Material atap, fasad, lantai dan balok menggunakan Cross Laminated Timber (CLT) juga untuk menciptakan kesan yang menyatu dengan alam dan untuk menyerap karbon. Pada bangunan penerima menggunakan struktur bangunan dari bambu petung dan penutup atap rumbia. Fasad bangunan menggunakan kombinasi antara membrane dan juga kaca $20 \mathrm{~mm}$ untuk memberikan variasi bayangan serta pencahayaan alami yang masuk ke bangunan (diffuse light). Kebutuhan listrik bangunan menggunakan solar panel, energi yang dihasilkan dari incinerator, serta PLN.

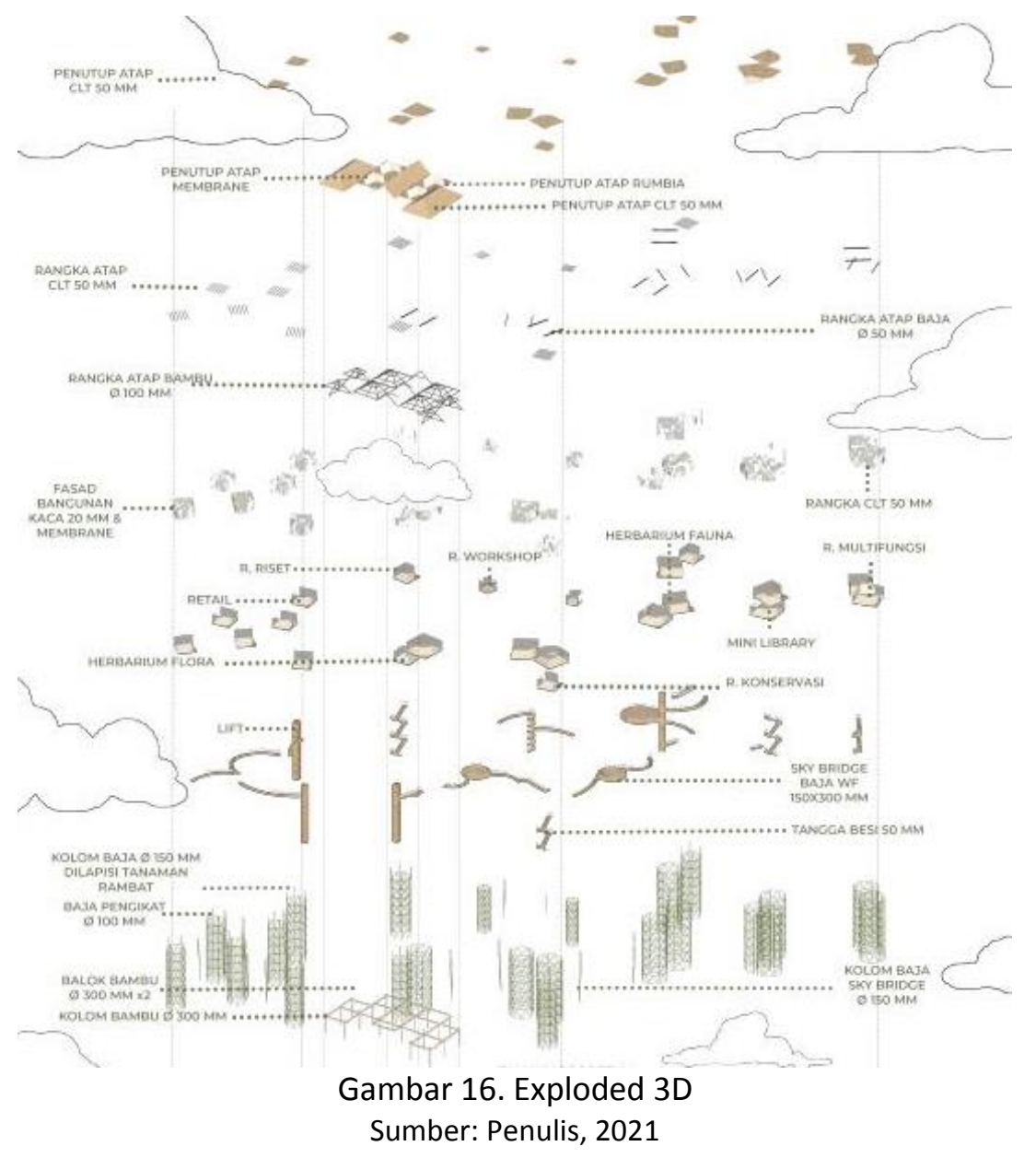

Escalated Urban Forest dan Exploratorium at Pamulang merupakan sebuah hutan kota dan exploratorium alam yang terletak di Pamulang, Tangerang Selatan. Melalui proyek ini, diharapkan dari sisi pengelola maupun pengunjung dapat menyadari esensi dari hutan kota dan pentingnya menjaga lingkungan alam dalam konteks ini adalah hutan kota, yang dimana memiliki banyak manfaat bagi kehidupan. Proyek ini memfasilitasi masyarakat dengan adanya habitat hewan dan tumbuhan, dimana pengunjung dapat berinteraksi langsung, 
mempelajarinya serta menjaganya. Taman sensori yang juga sebagai akses masuk dari wisata perternakan kuda sebagai taman dengan lima komponen alam pembentuk yang dapat menstimulasi indera yang dimiliki oleh manusia. Terdapat area pengetahuan yang terdiri dari perpustakaan kecil, dimana pengunjung dapat mengeksplorasi lebih pengetahuan mengenai alam dan lingkungan melalui media bacaan, dilanjutkan dengan ruang konservasi dan riset yang digunakan sebagai riset dan pengembangan baik makhluk hidup maupun lingkungan sekitar yang masih sangat terikat dengan kehidupan dan ruang workshop dimana masyarakat memiliki pengalaman pembelajaran yang berbeda yaitu dengan metode learning by doing.

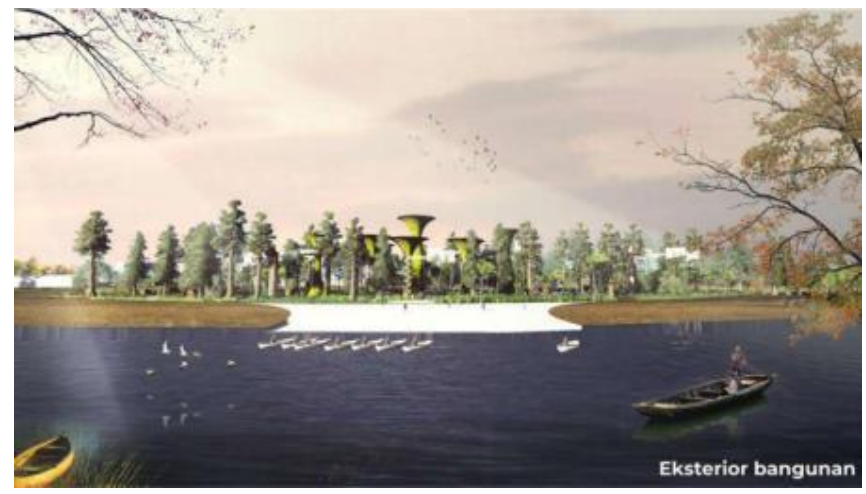

Gambar 17. Perspektif Eksterior Bangunan Sumber: Penulis, 2021

Dilanjutkan dengan area focal point pada tapak yang terdiri dari taman arboretum, super tree, taman biodinamis serta galeri herbarium sebagai media untuk merawat dan media pembelajaran keanekaragaman hayati yang dimiliki oleh hutan kota dan lingkungan sekitar serta pada sisi lain memiliki dampak pada lingkungan, yaitu dengan pengaplikasian super tree yang terintegrasi dengan bangunan untuk mengurangi emisi pada udara, taman biodinamis yang terdiri dari berbagai macam tumbuhan buah-buahan dan sayuran yang hasilnya bisa digunakan untuk keperluan di hutan kota atau untuk masyarakat setempat. Taman arboretum sebagai habitat dari flora dan juga sebagai media pembelajaran serta galeri herbarium yang terdiri dari berbagai macam jenis flora dan fauna yang dipajang dengan berbagai macam cara untuk menyampaikan informasi pengetahuan baru.

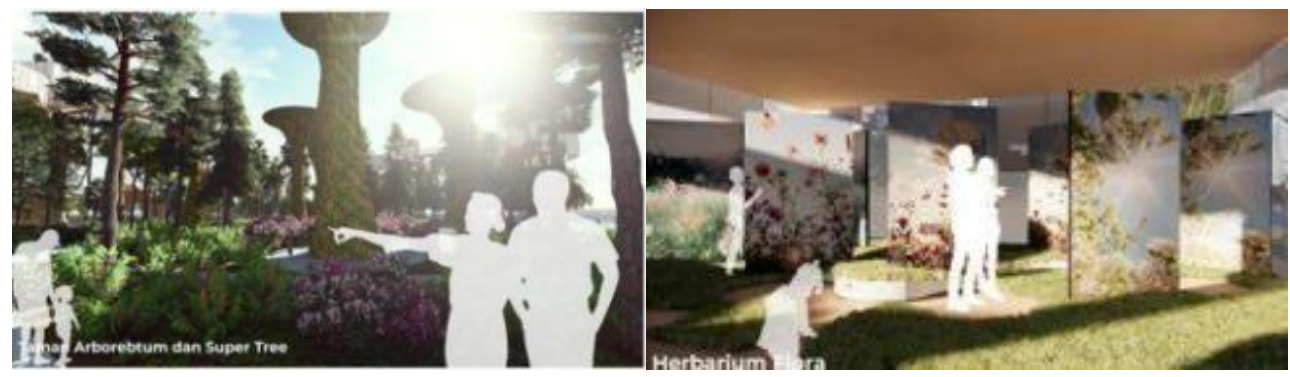

Gambar 18. Perspektif Suasana Dalam Proyek

Sumber: Penulis, 2021

\section{KESIMPULAN DAN SARAN}

\section{Kesimpulan}

Untuk mencapai keseimbangan ekosistem dan kehidupan yang lebih baik, dibutuhkan peran dari semua makhluk hidup (manusia, tumbuhan dan hewan) yang memiliki tanggung jawab dan kewajibannya masing-masing. Hutan kota yang memiliki banyak fungsi dan manfaat bagi lingkungan sekitar dan kota, dalam hal ini juga menjawab permasalahan menipisnya ruangruang terbuka hijau akibat perilaku manusia yang konsumtif dan tidak peduli lingkungan yang terjadi di kota-kota besar, salah satunya Tangerang Selatan dengan kecamatan Pamulang yang 
masih memerlukan pengembangan RTH untuk kedepannya. Escalated Urban Forest dan Exploratorium at Pamulang hadir sebagai generator dan kontribusi untuk kota dalam menjaga RTH dan memaksimalkannya sehingga memiliki dampak yang besar untuk alam dan makhluk hidup lainnya. Hal ini ditunjang dengan program proyek yang juga berkontribusi dalam agenda dunia (SDG's), perancangan massa bangunan yang kecil dan terpecah mengikuti posisi pohon eksisting dan pengangkatan ketinggian 10-20 meter diatas tanah. Kemudian dengan penggunaan material ramah lingkungan, hemat energi seperti bambu petung dan juga yang dapat menyerap karbon yaitu Cross Laminated Timber (CLT). Menanam pohon yang tergolong dalam fast growing species untuk memenuhi kebutuhan pohon dalam hutan kota yang dibantu dengan bioteknologi transformasi genetika dapat mempercepat pertumbuhan pohon hingga $2 x$ lipat. Hubungan integrasi sistem bangunan dengan super tree yang diaplikasikan pada proyek ini agar dapat menghasilkan energi sendiri untuk mengurangi emisi, mendaur ulang bio waste dan air hujan untuk kebutuhan di hutan kota dan juga bangunan.

Proyek ini memerlukan rencana dan penelitian yang lebih terhadap aspek biologis seperti karakteristik tumbuhan dan pohon terkait dengan cara perawatan, pembibitan, dan kegunaan lain sehingga tidak terjadi kesalahan dalam implementasinya dalam hutan kota. Selain itu juga terhadap media pembelajaran yang bisa dikembangkan lebih mudah dan praktis dengan target usia generasi $z$ dan alpha. Maka dari itu, Escalated Urban Forest dan Exploratorium at Pamulang ini dapat menjadi terobosan baru yang dapat dicontoh bagi pengembangan RTH kedepannya sebagai wujud usaha dalam menjaga ekologi lingkungan hidup yang dapat berdampak positif secara global bagi kota, lingkungan dan makhluk hidup.

\section{Saran}

Dalam perancangan yang memiliki tujuan untuk menjaga ekosistem kota ini, perlu diperhatikan beberapa aspek-aspek penting dalam fungsi dan elemen pembentuk hutan kota terkait dengan kondisi lahan, udara, topografi, dll. Selain itu juga diperlukannya pemahaman konteks tentang kawasan setempat yang dapat diimplementasikan ke dalam proyek agar dapat mempertahankan citra kawasan serta masyarakatnya. Dalam proyek ini juga terdapat beberapa kekurangan seperti, aspek keamanan (bangunan yang tinggi) yang berhubungan dengan intervensi lahan, maka sebaiknya perlu ada pertimbangan lebih mengenai aspek keamanan bagi pengguna namun juga tetap meminimalisir intervensi lahan hijau di kota.

\section{DAFTAR PUSTAKA}

Charter, B. (1999). The Burra Charter: the Australia ICOMOS Charter of places of cultural significance. Australia: ICOMOS.

Fajarianto, J. S. (2015). Identifikasi Kualitas Lingkungan Fisik Hutan Kota Srengseng sebagai Ruang Terbuka Publik. Jurnal Seminar Arsitektur '72, Vol. 1 No. 1.

Grey, G. W., \& Deneke, F. I. (1978). Urban Forestry. New York: John Wiley and Sons.

Hastanto, S. (2013). Pemanfaatan Hutan Kota Sebagai Bentuk Ruang Terbuka Hijau Dalam Mendukung Fungsi Perlindungan Lingkungan.

Kellert, S. R., Heerwagen, J. H., \& Mador, M. L. (2008). Biophilic Design: The Theory, Science and Practice of Bringing Buildings to. New York: John Wiley \& Sons Inc.

Mohhamad, K. (2012). Kajian Hutan Kota Dalam Pengembangan Kota Demak.

Nurlaili. (n.d.). Peranan Hutan Kota Dalam Peningkatan Kualitas Hidup. Lhokseumawe:

Politeknik Negeri Lhokseumawe.

Purnomohadi, N. (2002). RTH Sebagai Unsur Utama Pembentuk Kota yang Nyaman, Produktif dan Berkelanjutan. Jakarta: Kementrian PU.

Purnomohadi, N. (2002). Ruang Terbuka Hijau: Sebagai Unsur Utama Tata Ruang Kota. Jakarta: Kementrian PU.

Susanto, A. (2021). Dromologi Spatial. Jakarta 
Zoer'aini, D. I. (2008). Peranan Bentuk dan Struktur Kota terhadap Kualitas Lingkungan Kota disertasi. Bogor: IPB.

Andrian, E., (2003), Exploratorium di Yogyakarta, https://dspace.uii.ac.id/bitstream/handle/123456789/21120/97512042\%20Edwin\%20Andi an.pdf?sequence $=1$

Indonesia, P., (2002), Peraturan Pemerintah Republik Indonesia Nomor 63 Tahun 2002 Tentang Hutan Kota, http://widyacipta.com/file-pdf/PP\%20No_63_2002_hutan_kota.pdf

LIPI, (2010), Bioteknologi: Mempercepat Pertumbuhan Sengon Tumbuh 2 Kali Lipat, http://lipi.go.id/berita/bioteknologi-:-mempercepat-sengon-tumbuh-2-kali-lipat/4879

Martono, M., (2020), Ecology, Ecosystem, https://martonomily.com/2020/11/11/ecologyecosystem/

PLPG, (2016), Pembangunan Hutan Tanaman: Jenis Pohon Tumbuh Cepat, http://www.ucarecdn.com/4349faca-6d56-4f0d-b3ba-3c59ec3fa4cb/

Santoso, D. R., (2015), Program Perencanaan dan Perancangan Gedung Konservasi dan Pameran,http://eprints.undip.ac.id/46717/6/6)_Dewantoro_Respati_Santoso_2102011012 0073_BAB_V.pdf

Setiawan, P., (2021), Pengertian Ekologi dan Menurut Para Ahli, diunduh 17 Juni 2021, https://www.gurupendidikan.co.id/pengertian-ekologi/

Sustainable Development Goals, (2015), https://www.sdg2030indonesia.org/ 
